\title{
The Conus Toxin Geographutoxin II Distinguishes Two Functional Sodium Channel Subtypes in Rat Muscle Cells Developing in vitro
}

\author{
Tohru Gonoi, ${ }^{1}$ Yasushi Ohizumi, ${ }^{2}$ Hideshi Nakamura, ${ }^{2}$ Jun'ichi Kobayashi, ${ }^{2}$ and William A. Catterall' \\ Department of Pharmacology, University of Washington, Seattle, Washington 98195; and "Mitsubishi-Kasei Institute of \\ Life Sciences, 11 Minamiooya, Machida-shi, Tokyo 194, Japan
}

\begin{abstract}
Sodium currents in cultured rat muscle cells converted to myoballs by treatment with colchicine were recorded using a giga-ohm seal voltage-clamp procedure in the whole-cell configuration. Geographutoxin II (GTX II), a novel polypeptide toxin from the piscivorous marine snail Conus geographus, reduces sodium currents in rat myoballs without marked alteration of the time course or voltage dependence of activation of the remaining current. Titration of the inhibition of sodium currents by GTX II showed that, in individual myoballs, a fraction of the sodium current averaging $49 \pm 9 \%$ (SEM) was inhibited by saturating ( $25 \mu \mathrm{M})$ concentrations of GTX II. The concentration-effect curve fit a noncooperative, 1:1 binding isotherm with a single $K_{D}$ for GTX II of $19 \mathrm{nM}$ characteristic of inhibition of the TTX-sensitive sodium channels of adult rat muscle. Titration of the sodium current remaining in the presence of $2.5 \mu \mathrm{M} \mathrm{GTX} \mathrm{II} \mathrm{with} \mathrm{TTX} \mathrm{gave}$ complete inhibition. The dose-response curve fit a noncooperative, $1: 1$ binding isotherm with a single $K_{D}$ for TTX of $1.3 \mu \mathrm{M}$ characteristic of TTX-insensitive sodium channels of embryonic muscle. The action of GTX II was not frequency dependent. The all-or-none inhibition of these 2 sodium channel subtypes by GTX II suggests substantial structural differences in the region of neurotoxin receptor site 1 on TTX-sensitive and -insensitive sodium channels and provides definitive evidence that these 2 sodium channel subtypes function in parallel in muscle cells developing in the absence of innervation.
\end{abstract}

Two pharmacologically distinct subtypes of voltage-sensitive sodium channels have been described in mammalian muscle cells. The TTX-sensitive sodium channels of adult muscle are blocked by TTX binding at neurotoxin receptor site 1 with an apparent $K_{D}$ of approximately 10-20 nM (reviewed by Ritchie and Rogart, 1977). Denervation of adult muscle causes appearance of TTX-insensitive sodium channels with apparent $K_{D}$ values of approximately $1 \mu \mathrm{M}$ for TTX (Harris and Thesleff, 1971; Pappone, 1980). TTX-insensitive sodium channels are also present in fetal rat muscle developing in vivo (Harris and Marshall, 1973). Dissociated cultures of rat muscle cells developing in vitro express both TTX-insensitive sodium channels (Kidokoro et al., 1975; Catterall, 1976; Sastre and Podleski, 1976; Stallcup and Cohn, 1976) and TTX-sensitive sodium

Received July 21, 1986; revised Nov. 7, 1986; accepted Dec. 15, 1986.

This work was supported by a grant from the Muscular Dystrophy Association to W.A.C.

Correspondence should be addressed to William A. Catterall at the above address.

Copyright $\odot 1987$ Society for Neuroscience $0270-6474 / 87 / 061728-04 \$ 02.00 / 0$ channels (Frelin et al., 1983; Sherman et al., 1983), which function in parallel as assessed by ion flux (Sherman et al., 1983), voltagc-clamp (Gonoi et al., 1985); and single-channel recording (Weiss and Horn, 1986) methods.

Venom of the marine snail Conus geographus contains polypeptide toxins of novel structure (Nakamura et al., 1983; Sato et al., 1983; Cruz et al., 1985) that inhibit skeletal muscle contraction (Nakamura et al., 1983) by preferentially blocking muscle sodium channels (Minoshima et al., 1984; Cruz et al., 1985). Sodium channels in neuronal preparations are not blocked at similar toxin concentrations (Cruz et al., 1985; Ohizumi et al., 1986a). Geographutoxin II (GTX II), the most potent of this family of conotoxins, competitively inhibits binding of ${ }^{3} \mathrm{H}$-saxitoxin to neurotoxin receptor site 1 on muscle sodium channels at concentrations similar to those that inhibit sodium channel function (Moczydlowski et al., 1986; Ohizumi et al., 1986b; Yanagawa et al., 1986). Saxitoxin binding to sodium channels in synaptosomes or superior cervical ganglion is unaffected at similar concentrations. Since saxitoxin and TTX bind similarly to sodium channels of nerve and adult skeletal muscle, GTX II is the first ligand that distinguishes between the structures of neurotoxin receptor 1 on sodium channels in these tissues. This toxin may therefore provide the most sensitive probe of structural differences in this site on sodium channel subtypes. In these experiments, we have examined the action of this toxin on TTX-sensitive and TTX-insensitive sodium channels in spherical myoballs (Fukuda et al., 1976) prepared from cultured rat muscle cells developing in vitro using the giga-ohm seal, whole-cell voltage-clamp procedure of Hamill et al. (1981) as described previously (Gonoi et al., 1985).

\section{Materials and Methods}

Materials. Geographutoxin II was purified as described previously (Sato et al., 1983) from venom of the marine snail $C$. geographus. The other materials were obtained from the following sources: TTX and calf skin collagen, Calbiochem; tetraethylammonium (TEA) chloride and colchicine, Sigma Chemical Co.; horse serum and newborn calf serum, $\mathrm{KC}$ Biological Inc.; and Dulbecco-Vogt modified Eagle's essential medium (DMEM), Grand Island Biological Co.

Primary cell culture. Skeletal muscle cells were obtained from the forelimbs of 20 -d-old embryonic rats and prepared as described previously (Lawrence and Catterall, 1981a). Cells were seeded at a density of $2 \times 10^{5}$ cells $/ 35 \mathrm{~mm}$ plastic dish (Falcon) coated with calf skin collagen. The culture medium consisted of $10 \%$ horse serum, $5 \%$ newborn calf serum, and $85 \%$ DMEM. The medium was changed every 2 d. After day 4 , the culture medium was supplemented with $0.1 \mu \mathrm{M}$ colchicine, resulting in formation of myoballs within $24 \mathrm{hr}$.

Voltage-clamp recordings. Voltage-clamp experiments were performed on myoballs formed from rat muscle cells maintained in culture for 1 1-13 d instead of 5-10 d as in the previous work (Gonoi et al., 1985). The culture medium was replaced with recording medium in 
which the concentration of $\mathrm{Na}^{+}$ions was reduced to $35 \mathrm{mM}$ by replacement with TEA (120 mM TEA-chloride, $30 \mathrm{~mm} \mathrm{NaCl}, 5 \mathrm{~mm} \mathrm{KCl}, 1.5$ $\mathrm{mm} \mathrm{CaCl}, 1.0 \mathrm{~mm} \mathrm{MgCl}, 5 \mathrm{~mm}$ glucose, $5 \mathrm{~mm}$ HEPES adjusted to $\mathrm{pH}$ 7.4 with $\mathrm{NaOH}$ ). This solution was used to reduce $\mathrm{Na}^{+}$current and thereby avoid series resistance artifacts resulting from the large sodium current in myoballs (Gonoi et al., 1985). Recordings were made at room temperature $\left(22-23^{\circ} \mathrm{C}\right)$ on myoballs with diameters of $18-24 \mu \mathrm{m}$, smaller than those used in the previous work (Gonoi et al., 1985).

The voltage clamp was based on the 1-pipette giga-ohm seal wholecell recording technique (Hamill et al., 1981). The EPC-7 List clamp circuit was used. Series resistance of pipettes was compensated by an internal feedback circuit. The internal pipette solution consisted of 85 $\mathrm{mm} \mathrm{CsF}, 60 \mathrm{~mm} \mathrm{CsCl}, 10 \mathrm{~mm} \mathrm{NaF}$, and $5 \mathrm{~mm}$ EGTA. The $\mathrm{pH}$ of the internal medium was adjusted to 7.2 with $\mathrm{CsOH}$. $\mathrm{K}^{+}$current was efficiently blocked by $\mathrm{Cs}^{+}$ions in the pipette. Tip resistances of the pipettes were about $200 \mathrm{k} \Omega$ in the bathing solution. $\mathrm{Na}^{+}$conductance $\left(g_{\mathrm{Na}}\right)$ was calculated from peak currents $\left(I_{\mathrm{Na}}\right)$ by the relation $g_{\mathrm{Na}}=I_{\mathrm{Na}} /\left(E-E_{\mathrm{Na}}\right)$, where $E$ is membrane potential and $E_{\mathrm{Na}}$ is the reversal potential of the $\mathrm{Na}^{+}$current measured for each $g_{\mathrm{Na}}$ determination.

For measurements of voltage-dependent activation of $\mathrm{Na}$ channels, the holding potential of the cell was maintained at $-100 \mathrm{mV}$. The membrane was hyperpolarized in a prepulse to $-160 \mathrm{mV}$ for $100 \mathrm{msec}$ to remove inactivation of $\mathrm{Na}$ channels and was then depolarized to test pulse potentials from -90 to $+60 \mathrm{mV}$ in intervals of $+10 \mathrm{mV}$ for 7 msec. The pulses were repeated at 1 sec intervals. The $\mathrm{Na}^{+}$currents increased up to $50 \%$ within 10 min after making a seal as the pipette solution exchanged with the intracellular fluid. Toxin inhibition measurements were initiated after steady amplitude of $\mathrm{Na}^{+}$currents was obtained. GTX II or TTX was dissolved in recording medium at 4-fold higher concentration than desired final concentrations and was added cumulatively to the dish. Care was taken to apply the toxin in multiple aliquots at several points at least $7 \mathrm{~mm}$ from the myoball. Usually the inhibition of $g_{\mathrm{Na}}$ by the toxins reached equilibrium within $4 \mathrm{~min}$, but 5-10 min was allowed before recording $\mathrm{Na}^{+}$currents for determination of $g_{\mathrm{Na}}$ at each concentration. The ratio of the maximum $\mathrm{Na}^{+}$conductance in the presence of the toxin to that before adding the toxin was plotted for each experiment. In cumulative TTX inhibition experiments in the presence of GTX II, GTX II was also added to the TTX solutions to keep the final concentration of GTX II constant.

\section{Results}

The primary structure of GTX II is illustrated in Figure 1. It is a 22 residue polypeptide containing 3 hydroxyproline residues, 3 positively charged arginine residues, and 3 disulfide bonds (Sato et al., 1983). The guanidine moieties of 2 of the arginine residues are likely to occupy similar positions in neurotoxin receptor site 1 of the sodium channel to the guanidine moictics of TTX and saxitoxin. The larger size of GTX II may provide other points of attachment that result in selective binding to sodium channel subtypes.

Rat muscle cells were dissociated from embryonic limb muscles and myoballs were prepared as described under Materials and Methods. A giga-ohm seal was formed on an individual myoball, and sodium currents were recorded over approximately $10 \mathrm{~min}$ while the intracellular solution exchanged with the pipette solution and the amplitude of sodium currents reached steady state. A family of sodium current responses elicited by depolarization to membrane potentials of -90 to $+60 \mathrm{mV}$ before toxin treatment is illustrated in Figure $2 A$. The sodium channel density and the kinetic and voltage-dependent parameters describing these sodium currents agreed closely with those measured previously (Gonoi et al., 1985). Addition of GTX II to a final concentration of $2.5 \mu \mathrm{M}$ in the recording medium caused a progressive reduction in the sodium current recorded

Arg-Asp-Cys-Cys-Thr-Hyp-Hyp-Arg-Lys-Cys-Lys-

Asp-Arg-Arg-Cys-Lys-Hyp-Met-Lys-Cys-Cys-Ala-NH

Figure 1. Primary structure of GTX II.
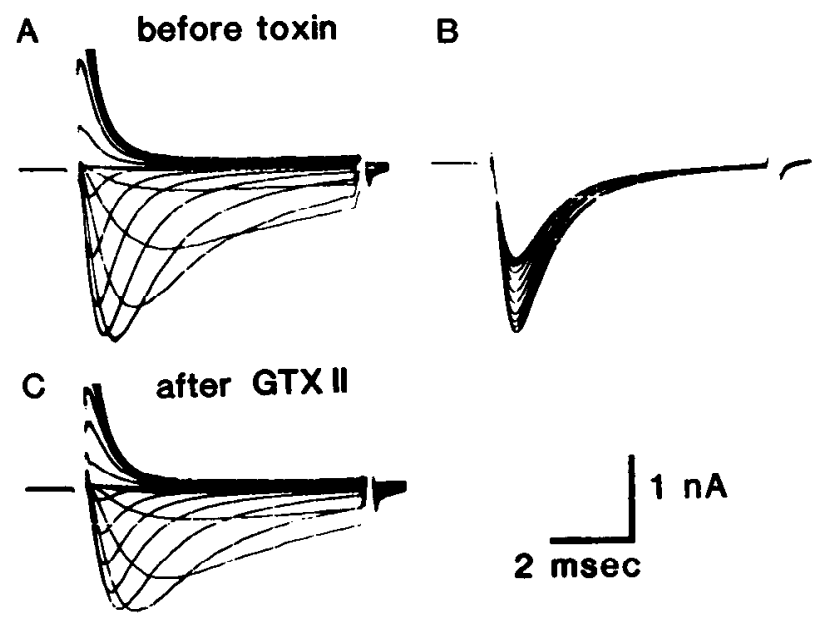

Figure 2. Sodium currents of a rat myoball under voltage-clamp conditions before and after applying GTX II. $A$, Family of sodium currents from myoball in a 13-d-old culture was recorded 10.5 min after making a seal between the myoball and a micropipette from a holding potential of $-100 \mathrm{mV}$ as described under Materials and Methods. B, GTX II, $167 \mu 1$ at $10 \mu \mathrm{M}$, in recording medium was applied from the outside of the myoball to give a final concentration of the toxin in the bath of $2.5 \times 10^{-6} \mathrm{M}$. Reduction of the sodium current after applying the toxin was monitored every $10 \mathrm{sec}$ by depolarizing the myoball to a test pulse potential of $-20 \mathrm{mV}$ for $7 \mathrm{msec}$ following a prepulse to $-160 \mathrm{mV}$ for $100 \mathrm{msec}$. The photograph presented was taken $3 \mathrm{~min}$ after applying GTX II and shows superimposed sodium currents. The peak sodium current decreased with each measurement after applying toxin until a new steady state was attained in $2 \mathrm{~min}$. $C$, Family of sodium currents 5 min after the application of GTX II from the same cell as in $A$ and $B$. Stimulus conditions were same as in $A$. Calibration bars are common to $A-C$.

at a pulse potential of $-20 \mathrm{mV}$. The sodium current reached a new steady state after approximately $2 \mathrm{~min}$ (Fig. $2 B$ ). Neither the time course nor the voltage dependence of the remaining sodium current was altered markedly by toxin treatment (Fig. 2C).

Cumulative addition of G'IX II to individual myoballs under voltage clamp caused progressive reduction in peak sodium conductance as illustratcd for 2 representative myoballs in Figure 3. After each addition, sodium conductance declined to a new steady state within $5 \mathrm{~min}$. Currents were recorded within 10 min after each addition. For the 2 myoballs illustrated, 61 and $35 \%$ of the sodium conductance were inhibited at a maximum concentration of GTX II. Concentration-effect curves, calculated by least-squares analysis assuming noncooperative $1: 1$ binding of GTX II to 61 and $35 \%$ of the sodium channels, respectively, fit the data closely and yield apparent $K_{D}$ values 21 and $27 \mathrm{~nm}$ for GTX II action on these 2 myoballs. These apparent $K_{D}$ values agree closely with those for block of contraction, sodium currents, and ${ }^{3} \mathrm{H}$-saxitoxin binding in adult muscle (Nakamura et al., 1983; Cruz et al., 1985; Ohizumi et al., 1986b) and therefore represent inhibition of TTX-sensitive sodium channels in the rat muscle cells.

In order to analyze the mean properties of a larger number of myoballs, 4 myoballs in different petri dishes were studied at each GTX II concentration and mean values of the ratio of sodium conductance in the presence and absence of GTX II were determined. Figure 4 illustrates the measured sodium conductance as a function of GTX II concentration. Analysis of these data as described above showed that $49 \pm 9 \%$ of the sodium conductance was inhibited with an apparent $K_{D}$ of 10 


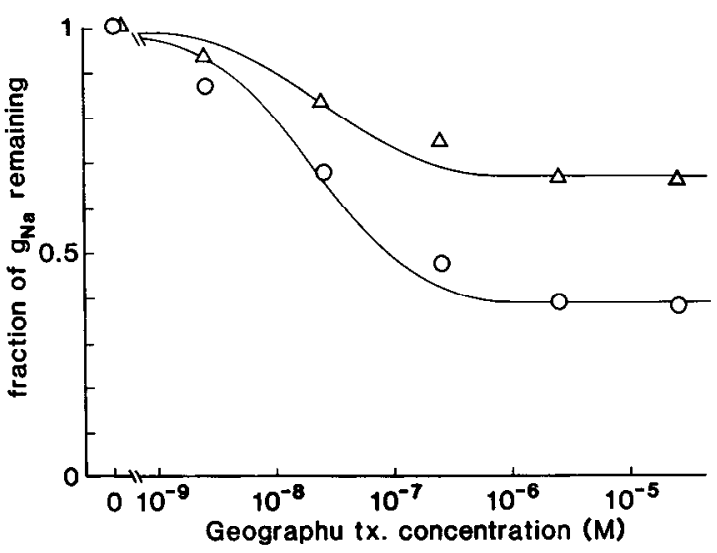

Figure 3. Inhibition of sodium conductance in individual myoballs by GTX II. Sodium currents were recorded from two 12-d-old myoballs as described under Materials and Methods. For each point, GTX II was added from a stock solution of $60 \mu \mathrm{M}$ in recording medium to achieve the final concentrations indicated. The smooth curves correspond to a least-squares fit of the data assuming a 1:1 binding of GTX II to a fraction $(F)$ of sodium channels: $\triangle, F=0.35, K_{D}=21 \mathrm{nM} ; \mathrm{O}, F=0.61$, $K_{n}=27 \mu \mathrm{M}$.

$\mathrm{nM}$, in agreement with the data from studies of individual myoballs.

These results show that individual myoballs contain 2 classes of sodium channels with respect to inhibition by GTX II. The sodium channels that are inhibited by GTX II have the same affinity for GTX II as the TTX-sensitive sodium channels in adult muscle. If TTX-sensitive sodium channels are preferentially inhibited by GTX II, the sodium channels remaining active in the presence of a saturating concentration of GTX II should all be the TTX-insensitive subtype. Figure 5 illustrates a concentration-effect curve for inhibition by TTX of the sodium conductance that remains in the presence of $2.5 \mu \mathrm{M}$ GTX II. In the cell cultures used for this experiment, $2.5 \mu \mathrm{M}$ GTX II reduced sodium conductance to $55.8 \pm 8.4 \%(\mathrm{SEM}, n=6)$ of control values. The sodium conductance that remained was unaffected

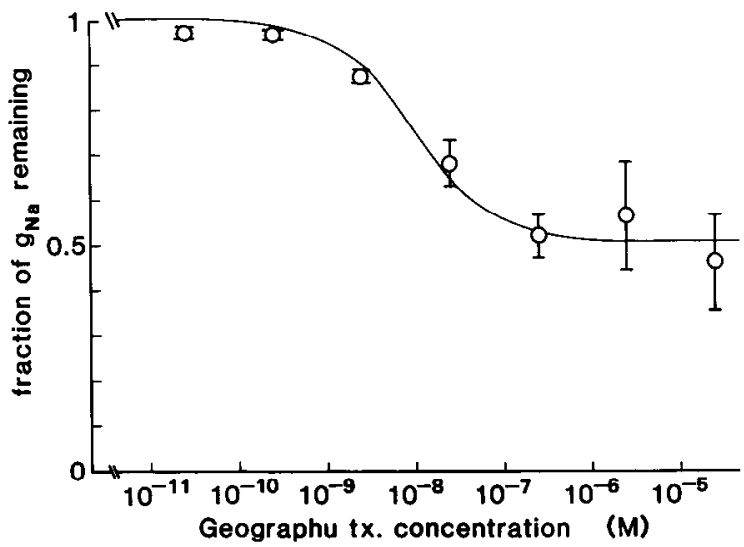

Figure 4. Concentration dependence of inhibition of sodium conductance by GTX II. Sodium currents were recorded from 28 myoballs as described under Materials and Methods. For each myoball, currents were recorded in recording medium and then in recording medium containing the indicated concentration of GTX II. The fraction of sodium conductance remaining in the presence of GTX II was calculated at each toxin concentration and the mean $( \pm S D)$ was calculated from the results on 4 myoballs at each concentration. The smooth curve was obtained by a least-squares fit of the data assuming a $1: 1$ binding of GTX II to a fraction $(F)$ of the sodium channels: $F=0.49, K_{D}=10$ nM.

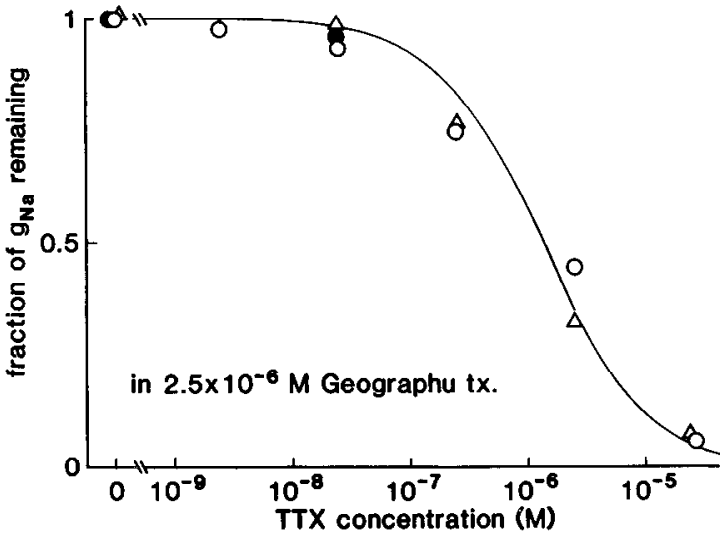

Figure 5. Concentration dependence of inhibition of sodium conductance by TTX in the presence of $2.5 \mu \mathrm{M}$ GTX II. Myoballs were incubated in the presence of $2.5 \times 10^{-6} \mathrm{M}$ GTX II at room temperature $\left(22-23^{\circ} \mathrm{C}\right)$ for $10 \mathrm{~min}$ before making a seal with a glass micropipette. After recording sodium currents in the presence of only GTX II, TTX concentration was increased cumulatively while the concentration of GTX II was kept constant and sodium currents were recorded. The different symbols represent different myoballs. The smooth curves in the figure represent a least-squares fit assuming 1:1 noncooperative binding of TTX to Na channels. $K_{D}$ was $1.3 \mu \mathrm{M}$ for TTX.

by $25 \mathrm{nM}$ TTX, indicating that no TTX-sensitive sodium channels remained active in the presence of $2.5 \mu \mathrm{M}$ GTX II (Fig. 5). The remaining sodium conductance was completely inhibited by higher concentrations of TTX with an apparent $K_{D}$ value of $1.3 \mu \mathrm{M}$, identical to that for block of TTX-insensitive sodium channels (Kidokoro et al., 1975; Catterall, 1976; Sastre and Podleski, 1976; Stallcup and Cohn, 1976; Pappone, 1980; Lawrence and Catterall, 1981a; Frelin et al., 1983; Sherman et al., 1983; Gonoi et al., 1985). The concentration-effect curve calculated assuming noncooperative, 1:1 binding to a single site fits the data closely. The results show that GTX II completely blocks the TTX-sensitive sodium channels in cultured rat muscle cells, leaving TTX-insensitive sodium channels unaffected.

Inhibition of TTX-insensitive sodium channels by TTX in heart (Cohen et al., 1981) and skeletal muscle (Gonoi et al., 1985) is frequency dependent, while inhibition of TTX-sensitive channels is not. We examined whether repetitive depolarization enhances block of sodium channels in myoballs by GTX II by stimulating with a train of 20 test pulses from a holding potential of -120 to $-20 \mathrm{mV}$ for $10 \mathrm{msec}$ at a frequency of $0.5,1$, or 2 $\mathrm{Hz}$. Similar conditions cause frequency-dependent block of TTXinsensitive sodium channels in myoballs by TTX (Gonoi et al., 1985). In the presence of $25 \mathrm{nM}, 2.5 \mu \mathrm{M}$, or $25 \mu \mathrm{M}$ GTX II, no enhancement of sodium channel inhibition by repetitive stimulation was observed. Thus, repetitive activation of sodium channels does not induce block of TTX-insensitive sodium channels by GTX II and the block of TTX-sensitive sodium channels by this agent is not frequency dependent under these conditions.

\section{Discussion}

Our results further establish GTX II as the most selective ligand for neurotoxin receptor site 1 on the sodium channel. Not only does this toxin distinguish clearly betwecn TTX-sensitive sodium channels in nerve and muscle (Cruz et al., 1985; Ohizumi et al., 1986a), but it also distinguishes more clearly between the TTX-sensitive and -insensitive sodium channels in rat muscle than does TTX itself. TTX binds to TTX-sensitive sodium 
channels with approximately 200 -fold higher affinity than TTXinsensitive sodium channels. GTX II binds to and inhibits TTXsensitive sodium channels with at least 10,000-fold higher affinity than TTX-insensitive sodium channels (Figs. 3, 4). It may have no action on TTX-insensitive sodium channels at all. These results provide the clearest evidence to date that the TTX-sensitive and -insensitive sodium channels in skeletal muscle are structurally distinct cntities. TTX-insensitive sodium channels in skeletal muscle have 3 additional properties that distinguish them from TTX-sensitive sodium channels. (1) They have higher affinity for Anemonia sulcata sea anemone toxin II than for Leiurus $\alpha$-scorpion toxin at neurotoxin receptor site 3 (Lawrence and Catterall, 1981a, b; Frelin et al., 1984). (2) Their inhibition by TTX is frequency dependent (Gonoi et al., 1985). (3) They have lower single-channel conductance and altered voltage-dependence (Weiss and Horn, 1986). TTX-insensitive sodium channels with similar properties are present in mammalian cardiac cells at all times (Reuter, 1979; Catterall and Coppersmith, 1981; Cohen et al., 1981). Considered together, these observations provide strong evidence that these 2 classes of sodium channels represent distinct pharmacological subtypes that are differentially expressed in muscle tissues.

The present results also provide the clearest evidence to date that rat muscle cells cultured in vitro in the absence of ncurons are able to synthesize functional TTX-sensitive sodium channels characteristic of adult skeletal muscle. In previous studies (Sherman et al., 1983; Gonoi et al., 1985; Weiss and Horn, 1986), the presence of functional forms of TTX-sensitive and -insensitive sodium channels in cultured muscle cells has been inferred from analysis of biphasic TTX inhibition curves, which revealed 2 components of sodium conductance with apparent $K_{D}$ values characteristic of these 2 channel subtypes. In contrast, GTX II gives all-or-none inhibition of these 2 channel subtypes, providing a definitive demonstration of the existence of 2 functional classes of channels. Evidently, rat muscle cells have the intrinsic capacity to synthesize functional TTX-sensitive sodium channels in the absence of innervation in vivo (Sherman and Catterall, 1982) and in vitro (Sherman et al., 1983; Gonoi et al., 1985; Weiss and Horn, 1986; this report). Innervation, and the electrical activity it stimulates in the muscle cell, regulates the cell-surface density of functional channels (Sherman and Catterall, 1982, 1984). GTX II will be a valuable experimental probe in further studies of this regulatory process.

\section{References}

Catterall, W. A. (1976) Activation and inhibition of the action potential $\mathrm{Na}^{+}$ionophore of cultured rat muscle cells by neurotoxins. Biochem. Biophys. Res. Commun. 68: 136-142.

Catterall, W. A., and J. Coppersmith (1981) Pharmacological properties of sodium channels in cultured rat heart cells. Mol. Pharmacol. 20: $533-542$.

Cohen C. J., B. P. Bcan, T. J. Colatsky, and R. W. Tsien (1981) Tetrodotoxin block of sodium channels in rabbit Purkinje fibers. J. Gen. Physiol. 78: 383-411.

Cruz, L. J., W. R. Gray, B. M. Olivera, R. D. Zeikus, L. Kerr, D. Yoshikami, and E. Moczydlowski (1985) Conus geographus toxins that discriminate between neuronal and muscle sodium channels. J. Biol. Chem. 260: 9280-9288.

Frelin, C., P. Vigne, and M. Lazdunski (1983) $\mathrm{Na}^{+}$channels with high and low affinity tetrodotoxin binding sites in the mammalian skeletal muscle cell. J. Biol. Chem. 258: 7256-7259.

Frelin, C., P. Vigne, H. Schweitz, and M. Lazdunski (1984) The interaction of sea anemone and scorpion neurotoxins with tetrodotoxinresistant $\mathrm{Na}^{+}$channels in rat myoblasts. Mol. Pharmacol. 26: 70-74.

Fukuda J., G. D Fischbach, and T. G. Smith (1976) A voltage clamp study of the sodium, calcium, and chloride spikes of chick skeletal muscle cells grown in tissue culture. Dev. Biol. 49: 412-424.

Gonoi, T., S. J. Sherman, and W. A. Catterall (1985) Voltage clamp analysis of tetrodotoxin-sensitive and -insensitive sodium channels in rat muscle cells developing in vitro. J. Neurosci. 5: 2559-2564.

Hamill, O. P., A. Marty, E. Neher, B. Sakmann, and F. J. Sigworth (1981) Improved patch-clamp techniques for high resolution current recording from cells and cell-free membrane patches. Pfluegers Arch. 391: 85-100.

Harris, J. B., and M. W. Marshall (1973) Tetrodotoxin-resistant action potentials in newborn rat muscle. Nature [New Biol.] 243: 191-192.

Harris, J. B., and S. Thesleff (1971) Studies on tetrodotoxin resistant action potentials in denervated skeletal muscle. Acta Physiol. Scand. 83: 382-388.

Kidokoro, Y., S. Heinemann, D. Schubert, B. L. Brandt, and F. G. Klier (1975) Synapse formation and neurotrophic effects on muscle cell lines. Cold Spring Harbor Symp. Quant. Biol. 40: 373-399.

Lawrence, J. C., and W. A. Catterall (1981a) Tetrodotoxin-insensitive sodium channels. Ion flux studies of neurotoxin action in a clonal rat muscle cell line. J. Biol. Chem. 256: 6213-6222.

Lawrence, J. C., and W. A. Catterall (1981b) Tetrodotoxin-insensitive sodium channels. Binding of polypeptide neurotoxins in primary cultures of rat muscle cells. J. Biol. Chem. 256: 6223-6229.

Minoshima, S., M. Kobayashi, H. Nakamura, J. Kobayashi, A. Ogura, M. Takahashi, and Y. Ohizumi (1984) Pharmacological effects of geographutoxin II isolated from the venom of Conus geographus on skeletal muscles. Jpn. J. Pharmacol. 36: 192.

Moczydlowski, E., B. M. Olivera, W. R. Gray, and G. R. Strichartz (1986) Discrimination of muscle and neuronal Na-channel subtypes by binding competition between $\left[{ }^{3} \mathrm{H}\right]$ saxitoxin and $\mu$-conotoxins. Proc. Natl. Acad. Sci. USA 83: 5321-5325.

Nakamura, H., J. Kobayashi, Y. Ohizumi, and Y. Hirata (1983) Isolation and amino acid compositions of geographutoxin I and II from the marine snail Conus geographus. Experientia 39: 590-591.

Ohizumi, Y., H. Nakamura, and J. Kobayashi (1986a) Presynaptic inhibitory effect of geographutoxin II, a new peptide toxin from Conus geographus venom, in the guinea-pig vas deferens. Eur. J. Pharmacol. 120: 245-248.

Ohizumi, Y., H. Nakamura, J. Kabayashi, and W. A. Catterall (1986b) Specific inhibition of $\left[{ }^{3} \mathrm{H}\right.$ lsaxitoxin binding to skeletal muscle sodium channels by geographutoxin II, a peptide channel blocker. J. Biol. Chem. 261: 6149-6152.

Pappone, P. A. (1980) Voltage-clamp experiments in normal and denervated mammalian skeletal muscle fibres. J. Physiol. (Lond.) 306 : $377-410$.

Reuter, H. (1979) Properties of two inward membrane currents in the heart. Annu. Rev. Physiol. 41: 413-424.

Ritchie, J. M., and R. B. Rogart (1977) The binding of saxitoxin and tetrodotoxin to excitable tissue. Rev. Physiol. Biochem. Pharmacol. 79: $1-49$.

Sastre, A., and T. R. Podleski (1976) Pharmacologic characterization of the $\mathrm{Na}^{+}$ionophores in $\mathrm{L} 6$ myotubes. Proc. Natl. Acad. Sci. USA 73: $1355-1359$.

Sato, S., H. Nakamura, Y. Ohizumi, J. Kobayashi, and Y. Hirata (1983) The amino acid sequences of homologous hydroxyproline-containing myotoxins from the marine snail Conus geographus venom. FEBS I ett. 15.5: 277-280.

Sherman, S. J., and W. A. Catterall (1982) Biphase regulation of development of the high affinity saxitoxin receptor by innervation in rat skeletal muscle. J. Gen. Physiol. 80: 753-768.

Sherman, S. J., and W. A. Catterall (1984) Electrical activity and cytosolic calcium regulate levels of tetrodotoxin-sensitive sodium channels in cultured rat muscle cells. Proc. Natl. Acad. Sci. USA 81: 262-266.

Sherman S. J., J. C. Lawrence, D. J. Messner, K. Jacoby, and W. A. Catterall (1983) Tetrodotoxin-sensitive sodium channels in rat muscle cells developing in vitro. J. Biol. Chem. 258: 2488-2495.

Stallcup, W. B., and M. Cohn (1976) Electrical properties of clonal cell line as determined by measurement of ionic fluxes. Exp. Cell Res. 98: 277-284.

Weiss, R. E., and R. Horn (1986) Functional differences between two classes of sodium channels in developing myoblasts and myotubes of rat skeletal muscle. Science 233: 361-364.

Yanagawa, Y., T. Abe, and M. Satake (1986) Blockade of $\left[{ }^{3} \mathrm{H}\right]$ lysinetetrodotoxin binding to sodium channel proteins by conotoxin GIII. Neurosci. Lett. 64: 7-12. 